\title{
PENGARUH PEMBERIAN "CONTRASH BATHING" TERHADAP PENURUNAN SPATISITAS OTOT LENGAN DAN TUNGKAI PADA ANAK DENGAN CEREBRAL PALSY
}

\author{
Afrianti Wahyu Widiarti, Yuliana Ratmawati \\ Kementerian Kesehatan Politeknik Kesehatan Surakarta Jurusan Fisioterapi
}

\begin{abstract}
Muscle spasticity, Contrash bathing, Cerebral palsy, Ashworth Scale. CP or cerebral palsy is a condition brain damage in childhood where there is a motor limitations caused by static lesions, non-progressive brain. CP showed abnormalities in muscle tone, causing a disturbance in the form of uncontrolled muscle tension or spasticity so that children are not able to perform functional movements. The aim of this study was to determine the influence of granting contrash bathing or showering in contrast with the water cold temperature (18 degrees Celsius) and the water warm temperatures (38 degrees Celsius) alternately with the duration of a specified time so that the muscles will experience the relaxation or muscle relaxation in the hope of limbs in children can be moved easily. There is the effect of bathing contrash therapy to decrease muscle spasticity in children with cerebral palsy. This study is a quasiexperimental study with two group pre and post test design. The subjects were all patients with CP in Yogyakarta WKCP that meets the criteria of inclusion, exclusion and drop out. The study was conducted for 8 weeks. Data collected were analyzed using SPSS 16.0. The different test within groups measured with Wilcoxon test, and for between groups measured with Mann Whitney test. The significance level was set on 0,05 . The Results is the contras bath can reduce spasticity muscles in your arms and legs to cerebral palsy $(p=0.011$ and $p=0.025$.
\end{abstract}

Keywords: Muscle Spasticity, Contrash Bathing, Cerebral Palsy, Ashworth Scale

\begin{abstract}
Abstrak: Spastisitas otot, Contrash bathing, Cerebral palsy, Skala Ashworth. CP atau cerebral palsy adalah sebuah kondisi kelayuhan otak pada masa kanak-kanak dimana terdapat keterbatasan motorik yang disebabkan oleh lesi statik, non progresif di otak. CP menunjukkan adanya abnormalitas tonus otot sehingga menyebabkan adanya gangguan berupa ketegangan otot yang tidak terkontrol atau spastisitas sehingga anak tidak mampu melakukan gerakan secara fungsional. Tujuan penelitian ini adalah untuk mengetahui besar pengaruh pemberian contrash bathing atau mandi kontras dengan air bertemperatur dingin (18 derajat celcius) dan air bertemperatur panas (38 derajat celcius) secara bergantian dengan durasi waktu yang sudah ditentukan sehingga otot akan mengalami pelemasan atau relaksasi otot dengan harapan anggota gerak pada anak tersebut dapat digerakan dengan mudah. Ada pengaruh pemberian terapi contrash bathing terhadap penurunan spastisitas otot pada anak dengan cerebral palsy. Penelitian ini adalah penelitian eksperimental semu dengan two group pre and post test design. Subyek penelitian adalah semua penderita CP di WKCP yogyakarta yang memenuhi criteria inklusi, eksklusi dan drop out. Penelitian dilakukan selama 8 minggu.
\end{abstract}


Uji beda dalam kelompok digunakan Wilcoxon test dan untuk antar kelompok digunakan Mann-Whitney test. Hasil dari penelitian contras bath dapat menurunkan spastisitas otot lengan dan tungkai pada cerebral palsy $(\mathrm{p}=0,011$ dan $\mathrm{p}=0,025)$.

Kata Kunci : Spastisitas Otot, Contrash Bathing, Cerebral Palsy, Skala Ashworth

\section{PENDAHULUAN}

Cerebral Palsy (CP) merupakan gangguan dari perkembangan otak yang bisa disebabkan karena infeksi atau karena trauma dimana otak masih dalam proses perkembangan atau belum matang (Soekarno, 2000). Miller (2005) menjelaskan dalam bukunya yang berjudul "Cerebral Palsy": CP adalah sebuah kondisi pada masa kanak-kanak dimana terdapat keterbatasan motorik yang disebabkan oleh lesi statik, non progresif di otak. Hal tersebut terjadi pada masa kanak-kanak awal, biasanya sebelum usia 2 tahun.

Di Indonesia, prevalensi penderita CP diperkirakan sekitar $1-5$ per 1.000 kelahiran hidup. Laki-laki lebih banyak daripada perempuan. Seringkali terdapat pada anak pertama. Hal ini mungkin dikarenakan kelahiran pertama lebih sering mengalami kesulitan dalam proses kelahiran. Angka kejadiannya lebih tinggi pada bayi berat badan lahir rendah dan kelahiran kembar. Umur ibu seringkali lebih dari 40 tahun, terlebih lagi pada multipara (Soetjiningsih, 1995, dalam Mardiani, 2006).

Kerusakan pada cortex cerebri akan mengakibatkan terjadi kontraksi otot secara terus menerus (spastis) yang disebabkan karena tidak terdapatnya inhibisi langsung pada arcus reflex. Bila terdapat cedera berat pada system extra pyramidal dapat menyebabkan gangguan pada semua gerak atau hypotonic, termasuk kemampuan bicara. Namun apabila hanya cedera ringan maka gerakan gross motor dapat dilakukan tetapi tidak terkoordinasi dengan baik dan gerakan motorik halus sering kali tidak dapat dilakukan. Gangguan proses sensorik primer yang terjadi di serebelum dapat mengakibatkan terjadinya ataksia. Pada keterbatasan gerak akibat fungsi motor control akan berdampak juga pada proses sensorik.

Tonus postural yang abnormal adalah berupa tidak terkontrolnya besar tonus saat otot berkontraksi yang terjadi pada setiap gerakan hal ini disebut dengan spastisitas otot.

Menurut Davidson, et al. (2003), ada beberapa metode pendekatan yang dapat digunakan sebagai manajemen penanganan pada pasien dengan gangguan neurologis. Beberapa contoh diantaranya yaitu teknik Proprioceptive Neuromuskuler Fascilitation (PNF), Motor Relearning Programe (MRP), Terapi Latihan dengan passive movement, Frenkle's exercise, Bobath konsep atau Neuro Developmental Treatment (NDT), dan sebagainya. Bobath konsep merupakan salah satu pendekatan yang paling umum digunakan (Raine, 2009). Dijelaskan oleh Sheperd (1995), dalam Hardiman (2013), menyatakan latihan yang terpenting dalam NDT adalah inhibisi spastisitas dan fasilitasi pola gerakan normal serta terutama persiapan untuk aktifitas fungsional. Konsep NDT memiliki 2 prinsip, yaitu : (1) normalisasi postur abnormal dan tonus otot dinamis yang mengarah pada gerakan normal dan eksplorasi gerak, (2) fasilitasi dari pola 
gerakan normal dalam aktifitas seharihari. Sedangkan teknik NDT meliputi : (1) inhibisi pada reflek yang abnormal, (2) fasilitasi reflek postural, (3) stimulasi propioseptif dan taktil dan juga, (4) key point of control.

Metode intervensi modalitas fisioterapi yang lain yang sering digunakan untuk menurunkan spastisitas otot adalah dengan mandi kontras atau contrash bathing, yaitu dengan memandikan anak dengan cara direndam dalam 2 buah bak secara bergantian dengan kedalaman air setinggi leher anak dengan suhu air pada bak pertama sebesar 4 derajat celcius (suhu netral air) dan bak kedua sebesar 35-40 derajat celcius. Penggunaan air dalam berbagai bentuk dan dalam berbagai suhu dapat menghasilkan efek yang berbeda pada sistem tubuh yang berbeda.

Dari beberapa intervensi yang telah disebutkan di atas, fisioterapilah yang mempunyai kompetensi untuk mengaplikasikan contrash bathing. Sehingga dalam penelitian ini diberi judul: "Pengaruh Pemberian Contrash Bathing untuk menurunkan spastisitas otot anggota gerak pada anak dengan cerebral palsy (CP)".

\section{METODE PENELITIAN}

Desain penelitian ini adalah two group pretest and postest design. Penelitian ini dilakukan pada komunitas CP di Yogyakarta yaitu pada Wahana Keluarga Cerebral Palsy (WKCP). WKCP berkantor di Jl. Ahmad Dahlan No. 123 Yogyakarta.

Populasi dalam penelitian ini adalah seluruh anggota Komunitas CP di Yogyakarta yaitu pada Wahana Keluarga Cerebral Palsy (WKCP). Sampel yang digunakan dalam penelitian ini adalah para penyandang $\mathrm{CP}$ yang dipilih melalui kriteria inklusi dan eksklusi.

Kriteria inklusi dalam penelitian ini adalah (1) pasien CP jenis kelamin laki-laki maupun perempuan, berusia di bawah 12 tahun, (2) pasien bersedia mengikuti program terapi selama kurang lebih enam minggu, (3) tidak mengalami gangguan sensibilitas, (4) nilai Asworth minimal 1

Kriteria eksklusi dalam penelitian ini adalah (1) pasien terdapat kejang, (2) pasien memiliki gangguan kognitif yang mengganggu jalannya penelitian.

Kriteria drop out dalam penelitian ini adalah (1) pasien tidak menyelesaikan latihan secara penuh, (2) pasien tidak hadir pada saat evaluasi akhir, (3) pasien tidak mengikuti latihan lebih dari lima kali.

Instrumen penelitian yang digunakan dalam penelitian ini adalah blanko pemeriksaan spastisitas otot. Penilaian spastisitas otot dengan skala Ashworth

Data yang dikumpulkan dianalisis dengan menggunakan bantuan software SPSS v16.0. Karena subyek tergolong bukan besar $(<30)$, maka sebaran data diasumsikan tidak berdistribusi normal, maka untuk uji beda dalam kelompok menggunakan Wilcoxon test dan untuk antar kelompok digunakan Mann Whitney test. Tingkat kemaknaan ditetapkan 0,05.

\section{HASIL PENELITIAN}

\section{Analisis Univariat}

Karakteristik subyek penelitian

Subyek penelitian ini adalah 20 (dua puluh) orang. 
Tabel 1

Karakteristik Subyek Penelitian Berdasarkan Umur

\begin{tabular}{|c|c|c|c|c|}
\hline \multirow[b]{2}{*}{ Usia } & \multicolumn{2}{|c|}{$\begin{array}{c}\text { Kelompok I } \\
\text { Contrash Bath }\end{array}$} & \multicolumn{2}{|c|}{$\begin{array}{c}\text { Kelompok II } \\
\text { Air netral }\end{array}$} \\
\hline & $\sum$ & $\%$ & $\sum$ & $\%$ \\
\hline $1-5$ & 5 & 50 & - & - \\
\hline $6-10$ & 4 & 40 & 8 & 80 \\
\hline $11-12$ & 1 & 10 & 2 & 20 \\
\hline Total & 10 & 100 & 10 & 100 \\
\hline
\end{tabular}

usia pada kelompok I didominasi oleh penderita dengan rentang usia 1-5 tahun berjumlah 5 orang (50\%), dan dengan penderita berusia 6-10 berjumlah 4 orang (40\%). Sedangkan pada kelompok II antara 1-5 adalah tidak ada ( $0 \%$ ), usia 610 ada 8 orang $(80 \%)$ dan usia $11-12$ ada 2 orang $(20 \%)$.

\section{Tabel 2}

Deskripsi Subjek Penelitian Berdasarkan Jenis Kelamin

\begin{tabular}{lcccc}
\hline & $\begin{array}{c}\text { Kelompok I } \\
\text { Contrash } \\
\text { Bath }\end{array}$ & $\begin{array}{c}\text { Kelompok II } \\
\text { Air netral }\end{array}$ \\
\hline Jenis Kelamin & $\sum$ & $\%$ & $\sum$ & $\%$ \\
Laki-laki & 4 & 40 & 5 & 50 \\
Perempuan & 6 & 60 & 5 & 50 \\
\hline \multicolumn{1}{c}{ Total } & $\mathbf{1 0}$ & $\mathbf{1 0 0}$ & $\mathbf{1 0}$ & $\mathbf{1 0 0}$ \\
\hline Tabel & \multicolumn{2}{c}{2,} & menggambarkan
\end{tabular}

karakteristik jenis kelamin subjek penelitian. Kelompok perlakuan I adalah 4 orang laki-laki (40\%) dan 6 orang perempuan (60\%). Pada kelompok perlakuan II adalah 5orang laki-laki (50\%) dan 5 orang perempuan $(50 \%)$.

Pada awal penelitian ini subyek diukur spastisitasnya dengan skala Ashworth. Deskripsi dari nilai Skala Ashworth sebelum perlakuan pada kelompok I diperoleh nilai untuk spastisitas lengan 1 maksimal 4 rata-rata 3 sedangkan untuk kelompok II diperoleh nilai minimal 1 maksimal 2 rata-rata 1 . Sedangkan spastisitas tungkai kelompok I diperoleh nilai minimal 1 maksimal 3 ratarata 2 sedangkan untuk kelompok II diperoleh nilai minimal 1 maksimal 3 ratarata 2. Hasil pengukuran awal subyek penelitian ini dapat dilihat pada tabel 3 sebagai berikut:

Tabel 3

Nilai Skala Asworth Sebelum

Perlakuan

\begin{tabular}{ccccccc}
\hline Kelompok & \multicolumn{1}{c}{ Minimal } & \multicolumn{3}{c}{ Maksimal } & \multicolumn{2}{c}{ Rata-rata } \\
\hline & L & T & L & T & L & T \\
I & 1 & 1 & 4 & 3 & 3 & 2 \\
II & 1 & 1 & 2 & 3 & 1 & 2 \\
\hline \multicolumn{3}{l}{ Setelah } & \multicolumn{3}{c}{ dilakukan } & \multicolumn{2}{c}{ perlakuan }
\end{tabular}
selama 8 minggu, nilai Skala Ashworth setelah perlakuan pada kelompok I diperoleh nilai untuk spastisitas lengan 1 maksimal 3 rata-rata 2 sedangkan untuk kelompok II diperoleh nilai minimal 1 maksimal 2 rata-rata 1 . Sedangkan spastisitas tungkai kelompok I diperoleh nilai minimal 1 maksimal 3 rata-rata 2 sedangkan untuk kelompok II diperoleh nilai minimal 1 maksimal 3 rata-rata 2 untuk lebih jelasnya dapat dilihat pada tabel 4.

\section{Tabel 4}

Nilai Skala Ashworth Setelah Perlakuan

\begin{tabular}{clllllll}
\hline Kelompok & \multicolumn{3}{l}{ Minimal } & \multicolumn{3}{c}{ Maksimal } & \multicolumn{2}{c}{ Rata-rata } \\
\hline & L & T & L & T & L & T \\
I & 1 & 1 & 3 & 3 & 2 & 2 \\
II & 1 & 1 & 2 & 3 & 1 & 2 \\
\hline
\end{tabular}

\section{Analisis Bivariat}

Uji beda sebelum dan sesudah perlakuan pada kelompok 1 pada lengan dan tungkai memiliki nilai $\mathrm{p}=0,011$ dan $p=0,025(p<0,05)$. Hal ini berarti bahwa Ho ditolak dan $\mathrm{Ha}$ diterima, sehingga dapat diartikan bahwa kelompok perlakuan 1 baik pada lengan dan tungkai 
terjadi penurunan spastisitas secara bermakna. Sedangkan pada kelompok 2 pada lengan dan tungkai memiliki nilai $\mathrm{p}$ $=0,317$ dan $\mathrm{p}=0,157(\mathrm{p}>0,05)$. Hal ini berarti bahwa Ho diterima dan $\mathrm{Ha}$ ditolak, sehingga dapat diartikan bahwa kelompok perlakuan 2 baik pada lengan dan tungkai tidak terjadi penurunan spastisitas secara bermakna.

\section{PEMBAHASAN}

Anak cerebral palsy mengalami gangguan pada sistem saraf pusat yang menyebabkan pengontrolan tonus otot tidak berjalan baik yang salah satu akibatnya menyebabkan hipertonus. Tonus otot yang berlebih menyebabkan otot secara spontan aktif, menghambat peregangan otot dan terus menerus dalam keadaan kontraksi, konsekuensinya sarkomer-sarkomer pada otot dapat menghilang sehingga menghambat pertumbuhan otot untuk memanjang, alhasil dapat menimbulkan kontraktur yang berimplikasi terhadap penurunan luas gerak sendi (Guyton dan Hall, 2012; Hagglund dan Wegner, 2011).

Hasil penelitian ini menunjukkan bahwa contras bath dapat menurunkan spastisitas otot lengan dan tungkai pada penderita cerebral palsy dengan diukur menggunakan skor skala Asworth $\mathrm{p}=$ 0,011 dan $p=0,025$. Hasil penelitian ini didukung oleh teori yang menjelaskan tentang efek contras bath yang mengkombinasikan antara air hangat dan air dingin secara bergantian dalam satu sesi terapi. Temperatur dingin akan menstimulasi ujung-ujung sensoris dibawah lapisan kulit yang akan mengakibatkan otot-otot berkontraksi (chill- menggigil) sebagai reaksi proteksi tubuh untuk menimbulkan panas agar suhu tubuh dapat konstan. Sedangkan temperatur panas akan menstimulasi sensoris di bawah kulit dengan reaksi berlawanan yaitu akan melemaskan otot agar terjadi dilatasi pembuluh darah perifer yang bertujuan untuk mencegah konduksi panas yang berlebihan pada tubuh. Bila kondisi tersebut terjadi secara berulang dengan tempo tertentu maka dapat mempengaruhi kerja ascenden dari sel schwan selubung axon dalam penghantaran rangsang menjadi lebih lambat yang pada akhirnya terjadi pelemasan otot (Trisnowiyanto, 2016).

Perubahan tingkat spastisitas dalam penelitian ini didapatkan akibat fasilitasi yang terjadi pada responden, yang didahului oleh impuls sensorik berupa sensasi panas dan dingin akibat informasi sensori yang secara rutin diberikan, reseptor pada otot dan kulit mengalami peningkatan nilai ambang rangsang (NAR) atau habituasi akibat sensasi yang baru. Sebagaimana kita ketahui bahwa secara fisiologis ketika otot diregangkan akan timbul refleks kontraksi akibat terstimulusnya muscle spindle, tepatnya reseptor sensori serabut saraf proprioreseptor tipe IA. Akibat eksitasi di reseptor tersebut mengakibatkan medulla spinalis bagian anterior merespon sehingga saraf motorik mengeksitasi otot untuk berkontraksi. Medulla spinalis bagian anterior merupakan bagian yang berperan dalam mengirimkan signal untuk pengaturan tonus otot. Anak CP memiliki control tonus terganggu akibat gangguan SSP, sehingga ketika medulla spinalis anterior menerima impuls, respon yang akan diberikan berlebih dan menimbulkan kontraksi yang kuat (Guyton dan Hall, 2012).

Namun demikian kelompok perlakuan dengan air netral tidak 
menunjukkan hasil yang signifikan dalam menurunkan spastisitas otot lengan dan tungkai, dengan diukur skala Ashworth $(\mathrm{p}=0,317)$ dan $(\mathrm{p}=0,157)$. Hal ini disebabkan oleh karena tidak adanya perubahan temperatur secara periodik yang akan menstimulasi sensoris dibawah kulit sehingga akan merangsang kerja ascenden dari sel schwan selubung axon dalam penghantaran rangsang menjadi lebih lambat yang pada akhirnya terjadi pelemasan otot.

\section{KESIMPULAN DAN SARAN}

Berdasarkan penelitian yang dilakukan pada 20 orang penderita cerebral palsy selama 8 minggu, dimana spastisitasnya dievaluasi dengan Skala Ashworth, diperoleh kesimpulan contras bath dapat menurunkan spastisitas otot lengan dan tungkai pada cerebral palsy.

Saran dari penelitian ini adalah (1) Saran untuk mendapatkan hasil kesimpulan yang komprehensif dan dapat dijadikan referensi, maka perlu dilakukan penelitian lanjutan dengan subyek yang lebih banyak dan dengan menggunakan alat ukur yang lebih valid dan reliabel serta dapat mengendalikan semua variabel pengganggu. Hasil penelitian ini dapat dijadikan bahan pertimbangan dalam penanganan kasus cerebral palsy khususnya untuk menurunkan spastisitas otot.

\section{DAFTAR RUJUKAN}

Guyton, Arthur., C., Hall, John., E; 2012. Buku Ajar Fisiologi Kedokteran. Jakarta: EGC72

Hagglund, Gunnar. Wegner, Philippe; 2011. Spasticity of the Gastrosoleus Muscle is Related to the Development of Reduced Passive Dorsoflexion of the Ankle in Children with Cerebral
Palsy. Acta Othopaedica. 82(6): 744-748

Mardiani, E; 2006. Faktor - faktor Risiko Prenatal dan Perinatal Kejadian Cerebral Palsy. Universitas Diponegoro Semarang.

Miller, Freeman; 2005. Cerebral Palsy. Nemours Foundation Wilmington. USA. Hal. 3.

Raine, et al; 2009. Bobath Concept : Theory and Clinical Practice in Neurological Rehabilitation. Blackwell Publishing Ltd. United Kingdom. Hal. 3.

Soekarno; 2000.Fisioterapi pada Cerebral Palsy Modifikasi Metode Bobath. Fakultas Kedokteran Universitas Airlangga. Surabaya.

Trisnowiyanto, Bambang; 2016. Rancang Program Terapi bagi Anak CP lewat Penilaian Kebutuhan. WKCP. Yogyakarta 